\title{
Mathematics and...
}

The vast majority of jobs of many flavours and incomes do not require the type of maths taught even in Grade 9. This is forgotten when mathematics is positioned as supremely important for the job market, or for students' personal development.

This view, expressed in a recent article in The Conversation by Sara Muller, a researcher and doctoral candidate at the University of Cape Town, is not one generally shared.

Scores of articles in the media, written by other experts, have pointed to the dangers of lowering the pass mark for mathematics, and the importance of at least some level of literacy in mathematics. Clive Kronenberg of the Cape Peninsula University of Technology, for example, wrote:

[Much research] illustrates the debilitating burden that generations of South African children have had to endure, from the apartheid era until the present day: an education system that has failed them. It has not inducted pupils into the custom of thinking and reasoning on logical, rational and critical terms. Critical thinking is a vital skill.

Research has shown that a well-cultivated critical thinker raises vital questions and problems, formulating them clearly and precisely. They are able to gather and assess relevant information, using abstract ideas to interpret it effectively. They can reach well-reasoned conclusions and solutions, testing them against relevant criteria and standards.

The relationship between 'mathematics education' and 'more complex thinking' is typically symbiotic and mutually inclusive. Good, productive mathematics education can positively raise pupils' skills in diagnostic, methodical thinking.

Ironically, it has also been pointed out recently that the levels of performance in the 'maths literacy' option are declining, just as is performance in the 'standard' mathematics courses. And, as is well known, South African schoolgoers perform close to the bottom of world measures of mathematics and language skills.

While it is probably true that there are many jobs that do not require reasonable levels of mathematical competence and the accompanying critical skills, many certainly do - and in some universities (the producers of high-level skilled employees), a surprising range of disciplines require some competence in mathematics or statistics. That students studying physics, chemistry, engineering, computer or information science, astronomy, oceanography and the animal and plant sciences need such competency is obvious. Increasingly, though, disciplines such as economics, palaeoanthropology, archaeology, psychology, education, geography and meteorology also require those skills.

Coming to terms with the value of mathematics in all varieties is not just a useful exercise then, but a critical part of education and of social and economic development. In view of the importance and significance of the mathematical sciences, the Academy of Science of South Africa (ASSAf) hosted a two-day workshop, in September 2016, entitled
'Finding Synergies in the Mathematical Sciences'. A primary aim of the workshop was to seek a discursive space to explore synergies in the mathematical sciences that could lead to interdisciplinary collaborations across various disciplines that include mathematics as a key pivot in their pursuits to understand, generate and use new knowledge. Explaining the importance of the workshop, ASSAf stated:

[There] is a global need for the mathematical sciences, which includes the discipline of mathematics, to work closer together to create discursive spaces to explore synergies and collaborations of mutual benefit. The mathematical sciences include all disciplines that use mathematics in their pursuits to understand, generate and use new knowledge. This includes disciplines from the natural sciences such as physics, biochemistry, and astronomy etc. to the social sciences such as economics, psychology, education, etc.

The workshop included the presentation of five papers each on the role of mathematics in a different field, by leading scientists in those fields. Each of these speakers was invited to revise their presentation for publication in the Journal and we are very pleased to be able to publish them as a set of Invited Commentaries in this issue.

Professor Jill Adler has written on 'Mathematics in mathematics education'; Professor Jan-Hendrik Hofmeyr on 'Mathematics and biology'; Professor Loyiso Nongxa on 'Mathematical and statistical foundations and challenges of big data sciences'; Professor Daya Reddy on 'Finding synergies between the mathematical and physical sciences'; and Professor Martin Wittenberg on 'Mathematics and economics: We should expect better models'.

Readers of the Journal will find each of the papers insightful and, it is to be hoped, a means for encouraging others (especially young scientists) to extend their knowledge of and interests in the mathematical sciences. In his commentary, Professor Reddy reminds readers that
[d]epending on one's sources, the mathematical historical record dates back to around 1200 BCE. We are more familiar in the West with the seminal contributions of ancient Greece, although the mathematical heritage of the Islamic world from the 8th century onwards has become increasingly better known. Nevertheless one finds, in many different parts of the world, evidence of mathematical activity dating from antiquity. A further example relates to the Mayan civilization of central America: evidence of mathematical activity there appears to date back at least to 50 BCE.

Mathematics is not just a discipline with a wide-ranging value, and a long history - but one that flourished, early on, in many parts of the world.

The proceedings report of the workshop is available here. 